\title{
Additive Manufacturing of Parts and Tooling in Robotic Systems
}

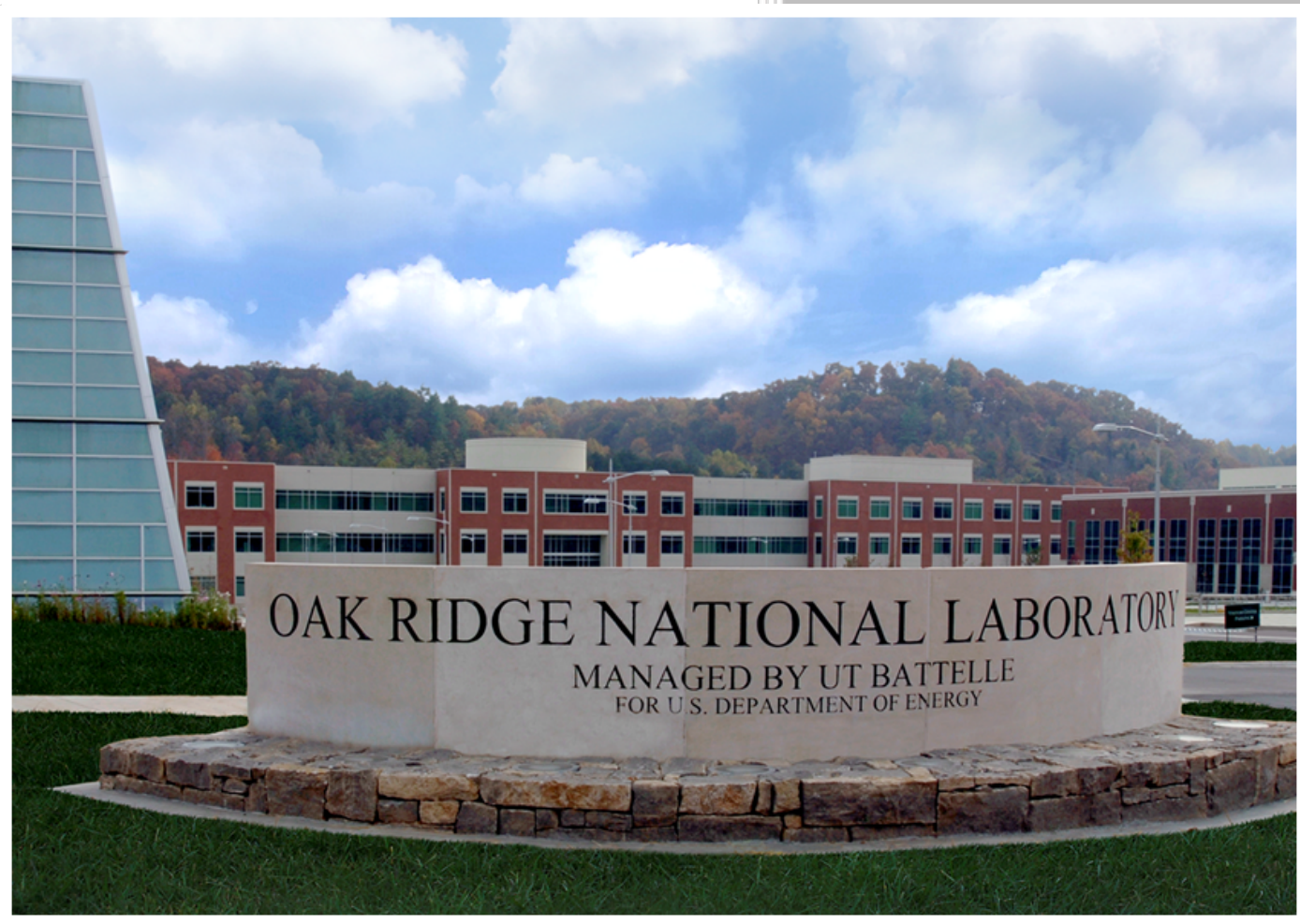

Brad Richardson

Dr. Lonnie Love

Dr. Ahmed Hassen

Phillip Chesser

Jeremy Parsons

Mantaro Networks, Inc.

March 30, 2018

CRADA FINAL REPORT NFE-16-06174

Approved for Public Release. Distribution is Unlimited. 


\title{
DOCUMENT AVAILABILITY
}

Reports produced after January 1, 1996, are generally available free via US Department of Energy (DOE) SciTech Connect.

Website http://www.osti.gov/scitech/

Reports produced before January 1, 1996, may be purchased by members of the public from the following source:

\author{
National Technical Information Service \\ 5285 Port Royal Road \\ Springfield, VA 22161 \\ Telephone 703-605-6000 (1-800-553-6847) \\ TDD 703-487-4639 \\ Fax 703-605-6900 \\ E-mail info@ntis.gov \\ Website http://www.ntis.gov/help/ordermethods.aspx
}

Reports are available to DOE employees, DOE contractors, Energy Technology Data Exchange representatives, and International Nuclear Information System representatives from the following source:

Office of Scientific and Technical Information

PO Box 62

Oak Ridge, TN 37831

Telephone 865-576-8401

Fax 865-576-5728

E-mail reports@osti.gov

Website http://www.osti.gov/contact.html

\begin{abstract}
This report was prepared as an account of work sponsored by an agency of the United States Government. Neither the United States Government nor any agency thereof, nor any of their employees, makes any warranty, express or implied, or assumes any legal liability or responsibility for the accuracy, completeness, or usefulness of any information, apparatus, product, or process disclosed, or represents that its use would not infringe privately owned rights. Reference herein to any specific commercial product, process, or service by trade name, trademark, manufacturer, or otherwise, does not necessarily constitute or imply its endorsement, recommendation, or favoring by the United States Government or any agency thereof. The views and opinions of authors expressed herein do not necessarily state or reflect those of the United States Government or any agency thereof.
\end{abstract}


ORNL/TM-2017/452

CRADA/NFE-16-06174

Energy and Transportation Science Division

Advanced Manufacturing Office

\title{
Additive Manufacturing of Parts and Tooling in Robotic Systems
}

\author{
Brad Richardson \\ Dr. Lonnie Love \\ Dr. Ahmed Hassen \\ Phillip Chesser \\ Jeremy Parsons \\ Mantaro Networks, Inc.
}

Date Published:

March 30, 2018

\author{
Prepared by \\ OAK RIDGE NATIONAL LABORATORY \\ Oak Ridge, Tennessee 37831-6283 \\ managed by \\ UT-BATTELLE, LLC \\ for the \\ US DEPARTMENT OF ENERGY \\ under contract DE-AC05-00OR22725
}

Approved For Public Release 



\section{CONTENTS}

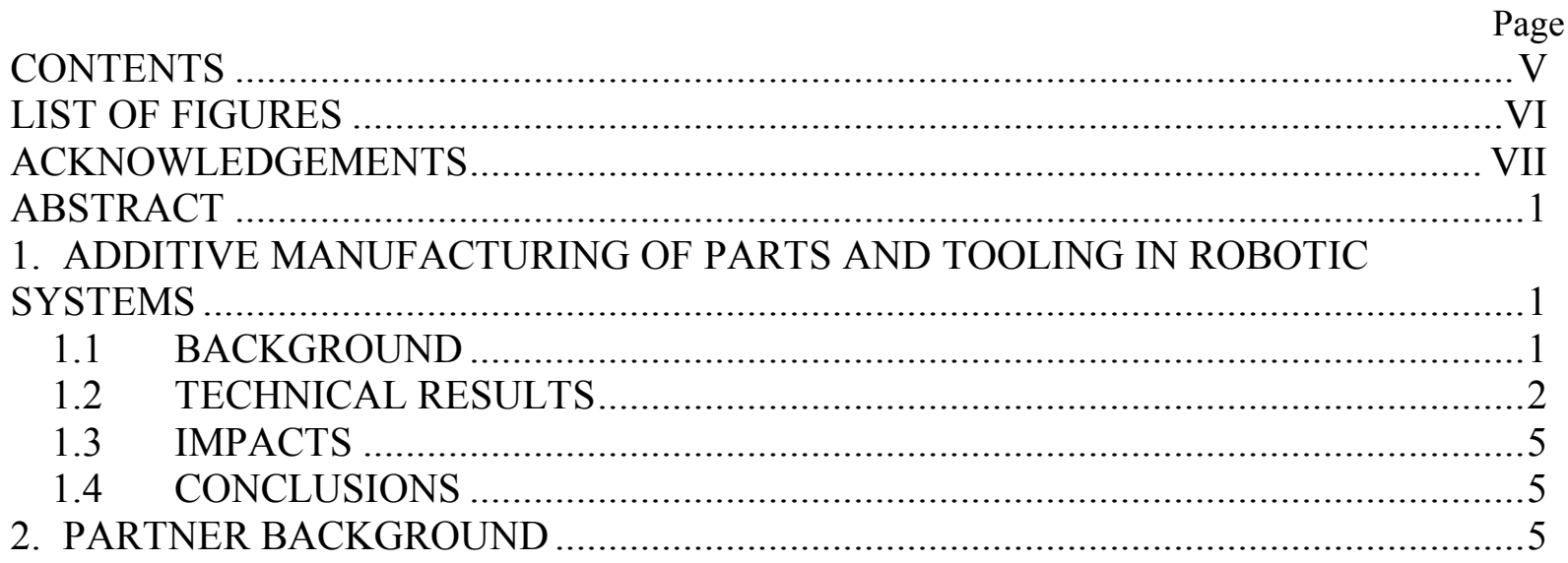




\section{LIST OF FIGURES}

Fig. 1. Model of the ARTI battery enclosure.............................................................. 2

Fig. 2. ARTI body printed out of ABS............................................................ 3

Fig. 3. ARTI body top and bottom assembled. ............................................................. 3

Fig. 4 Assembled ARTI climbing stairs ......................................................... 4 


\section{ACKNOWLEDGEMENTS}

This CRADA NFE-16-06174 was conducted as a Technical Collaboration project within the Oak Ridge National Laboratory (ORNL) Manufacturing Demonstration Facility (MDF) sponsored by the US Department of Energy Advanced Manufacturing Office (CPS Agreement Number 24761).

Opportunities for MDF technical collaborations are listed in the announcement "Manufacturing Demonstration Facility Technology Collaborations for US Manufacturers in Advanced Manufacturing and Materials Technologies" posted at http://web.ornl.gov/sci/manufacturing/docs/FBO-ORNL-MDF2013-2.pdf. The goal of technical collaborations is to engage industry partners to participate in shortterm, collaborative projects within the Manufacturing Demonstration Facility (MDF) to assess applicability and of new energy efficient manufacturing technologies. Research sponsored by the U.S. Department of Energy, Office of Energy Efficiency and Renewable Energy, Advanced Manufacturing Office, under contract DE-AC05-00OR22725 with UT-Battelle, LLC.

The authors would like to acknowledge the direction of Phillip Walker, CEO of Transcend Robotics and the input of Nathaniel Rogers of Mantaro Networks Inc. 


\begin{abstract}
ORNL worked with Transcend Robotics, LLC to explore additive manufacturing of the two-piece compression body for their ARTI mobile robot platform. Extrusion compression molding was identified as an effective means of manufacturing these parts. ORNL consulted on modifications to the housing design to accommodate the selected manufacturing process. Parts were printed using ORNL's FDM machines for testing and evaluation of the design as a precursor to molding the parts. The assembly and evaluation of the parts proved favorable and minor design changes to improve assembly and performance were identified.

The goal is to develop a light weight and rugged two-part robotic enclosure for an unmanned ground vehicle UGV) that will be used in search and rescue applications. The FDM parts fabricated by ORNL allowed Transcend Robotics to assemble a prototype robot and verify that the new parts will meet the performance requirements. ORNL fabricated enclosure parts out of ABS and Nylon 12 materials such that the design could be tested prior to fabricating tooling for compression molding of Nylon 6 with carbon fiber fill. The robot was performance tested and compared with the previous manufacturing techniques and found to have superior performance.
\end{abstract}

\title{
1. ADDITIVE MANUFACTURING OF PARTS AND TOOLING IN ROBOTIC SYSTEMS
}

This phase 1 technical collaboration project (MDF-TC-2016-090) was begun on April 1, 2016 and was completed on March 30, 2018. The collaboration partner Transcend is a small business. ORNL worked with Transcend to modify the design of their parts for their robotic system and printed parts for two prototype systems for evaluation.

\subsection{BACKGROUND}

Transcend Robotics is a small startup business with 5 employees founded in 2014 that focuses on cutting-edge robotics mobility technology. Transcend develops and sells robotic products including unmanned ground vehicles for law enforcement applications. In addition Transcend licenses their patented technology to other robot manufacturers. Mantaro Networks Inc. is a partner and licensee of Transcend and provided the engineering and test facilities to Transcend for testing the ORNL manufactured parts. Mantaro is a small company located in Germantown MD with a staff of 25.

Transcend Robotics has developed a hybrid tracked vehicle that overcomes some of the limitations of conventional tracked vehicles with a novel six track topology. Furthermore, the body is segmented into three sections with compliant couplings between the sections to enable passive conformal terrain matching providing great mobility enhancement. Segmenting the single track into three sections enables low friction turning capability. In addition, the passive compliance between the sections enables easy terrain maneuvering. The simplicity of the design enables great maneuverability without complex and expensive sensing and control. Applications include not only first responders and Department of Defense, but the technology is scalable to larger earth moving equipment.

The aim of this project was to explore the impact additive manufacturing can have on reducing the cost for low-volume production through direct part substitution during the first phase. A second phase is planned that will look at low-cost tooling through additive manufacturing.

A successful effort will result in a simpler design, reduced part count and lower cost low volume manufacturability. 


\subsection{TECHNICAL RESULTS}

Initially, the printability of a battery enclosure and related brackets were investigated. Parts were printed out of both ultem and polycarbonate and evaluated by Transcend. Both sets of parts were satisfactory. Figure 1 shows a model of the parts that were printed (all in yellow).

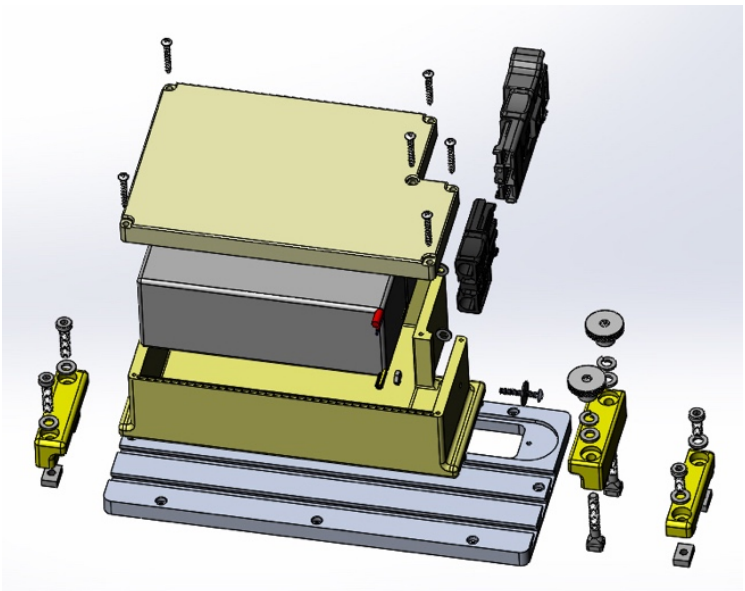

Fig. 1. Model of the ARTI battery enclosure.

The primary focus of the Phase 1 effort shifted to generate and print an ARTI body that could be manufactured efficiently and cost effectively. A series of conference calls, as well as a face to face meeting were held to review the Transcend design and to select an appropriate method to produce the design in Phase 2 and beyond, to iterate on the design and to print on ORNL's Fortus FDM (fused deposition modeling) machines prototypes of the new design.

The main manufacturing challenges that were confronted included reducing the number of different parts required to assemble the enclosure, reduce the weight, increase internal volume and increasing strength. The collaboration between ORNL and Transcend/Mantaro resulted in a design with a two-part enclosure with design features that:

- $\quad$ reduced the number of components to make an enclosure from 5 to 2 .

- $\quad$ increased internal volume allowing larger batteries and room for electronics

- $\quad$ reduced weight while increasing strength of enclosure

- $\quad$ reduced manufacturing cost of enclosure by $80 \%$

ORNL evaluated potential manufacturing options. Compression molding was selected as the preferred process for the two-piece body parts. The recommended material was nylon, reinforced with either glass or carbon fibers. The carbon provides for greater strength and is lighter, while the glass reduces costs. Iterations were made to the design to make it more amenable to the compression molding process. Design changes included minor changes in drafts, wall thicknesses and the way the two parts would be fastened together.

Parts were printed on Fortus machines for 2 robots ( 3 pairs for each). One set was printed in ABS, the other in Nylon-12. Figure 2 shows both the top and bottom parts, printed in ABS. Figure 3 shows the top and bottom assembled. 

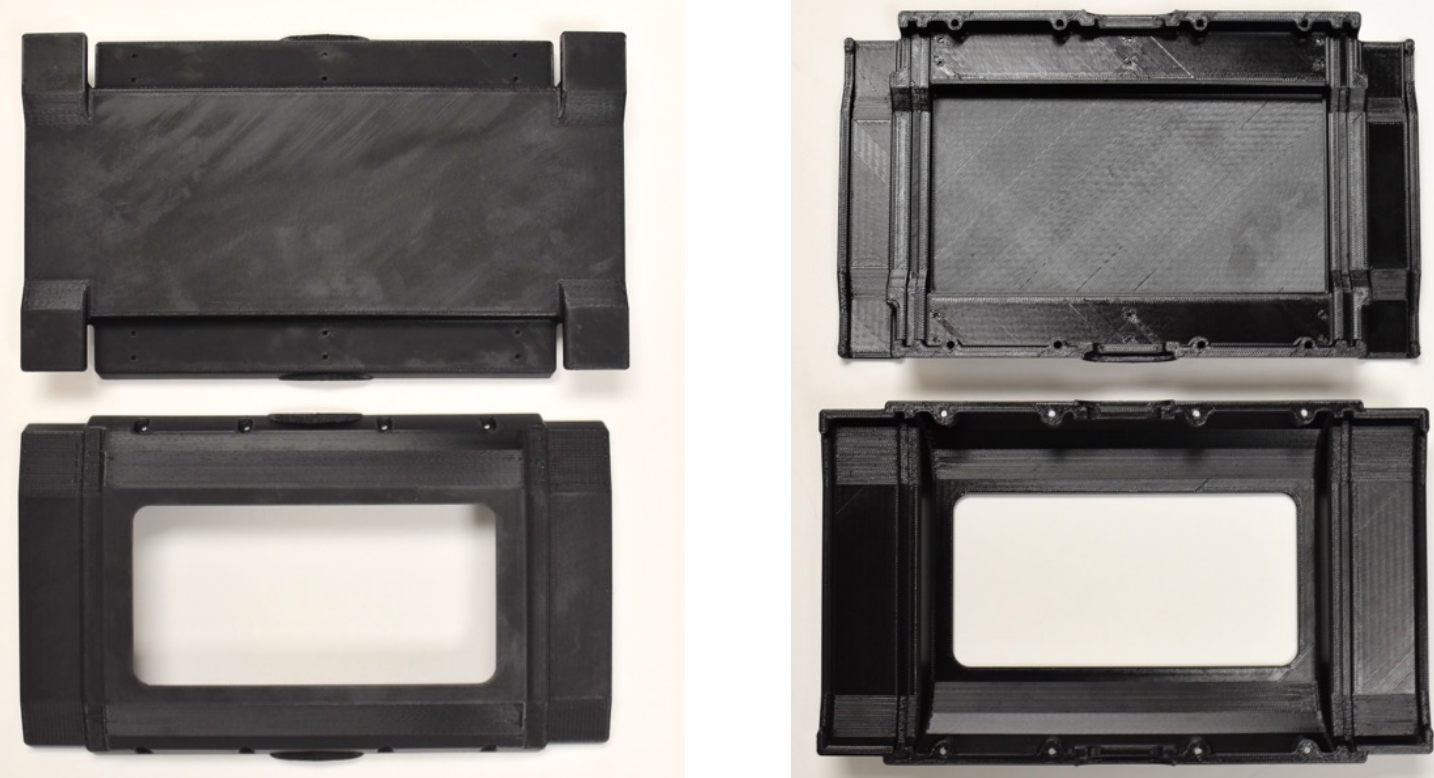

Fig. 2. ARTI body printed out of ABS.

Bottom piece above, top piece below.
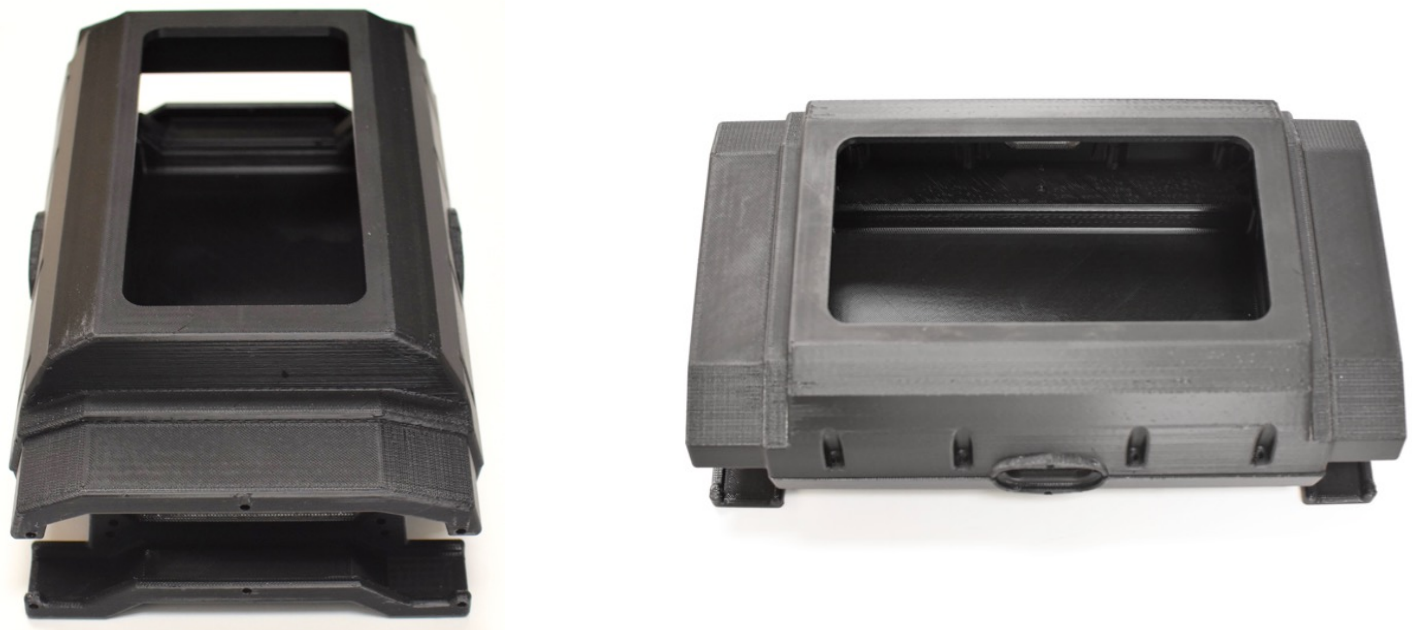

Fig. 3. ARTI body top and bottom assembled. 

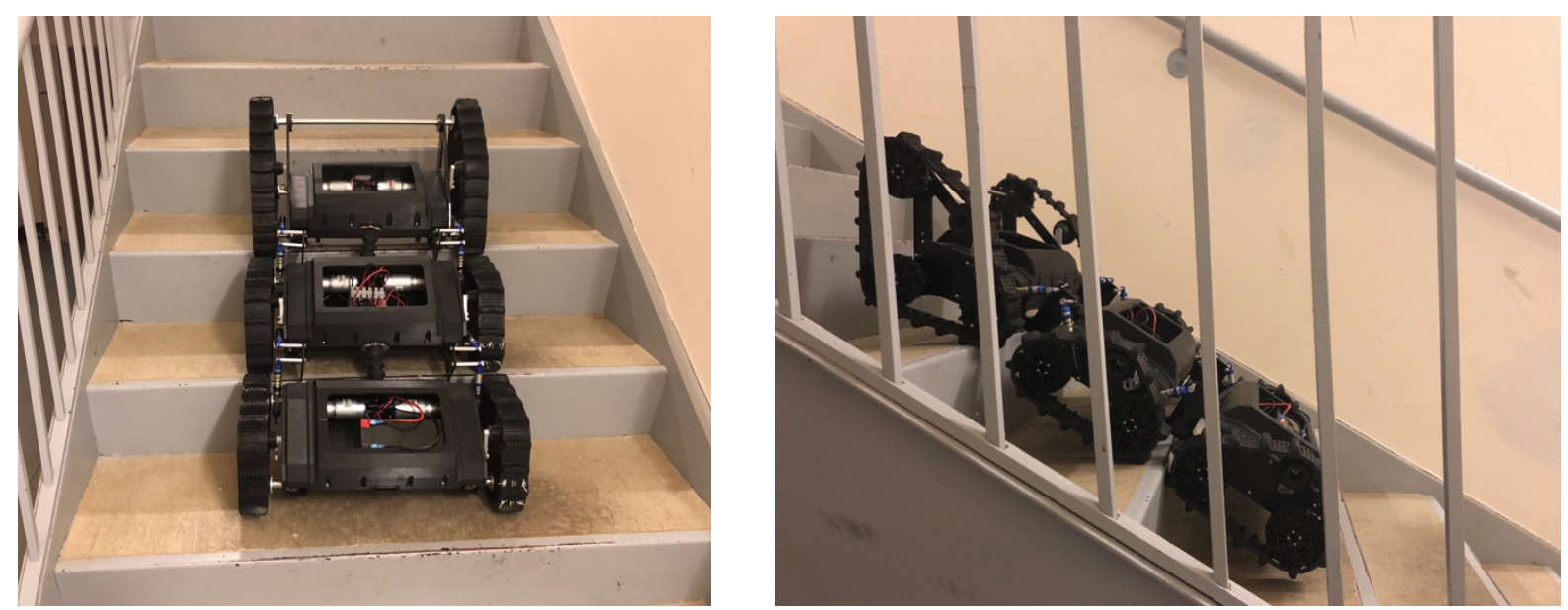

Fig. 4 Assembled ARTI climbing stairs

The ARTI robot was assembled using three sets of the ARTI enclosure. The ARTI was then performance tested to verify that it can climb stairs and that the enclosures will meet the performance requirements for search and rescue applications. During the testing efforts several design issues were uncovered and addressed with minor modifications to the enclosure. Most of the issues involved changes to the enclosure to accommodate requirements of other aspects of the design including accommodating COTS battery packs and accommodating additional room for control electronics.

The chart below shows some of the important material characteristics of the test materials and the planned final compression molded material. The test materials were $3 \mathrm{~d}$ printed so they are inherently weaker than the final compression molded material. However, the higher yield strength and Young's Modulus gave less ductility to ABS compared to nylon 12 which helps with the overall stability of the drive train connections. In the final compression mold parts the significantly higher values of the nylon 6 with 50\% carbon fiber fill will help with the rigidity of the crucial drivetrain mount points. Also due to the potential for drops and impacts in dangerous areas the increasing impact strength improves the enclosures overall performance. The increase in strength does come with an increase in weight which is shown by the specific gravity increase however it is not too major of an increase when compared to the specific gravity of a metal like 6061 aluminum at 2.7.

\begin{tabular}{|c|c|c|c|c|}
\hline & Test standard & $\begin{array}{c}\text { ABS (extruded) } \\
\text { Avallone (2007) }\end{array}$ & $\begin{array}{c}\text { nylon 12 (3d } \\
\text { printed strongest } \\
\text { direction) Stratsys } \\
\text { (2014) }\end{array}$ & $\begin{array}{c}\text { nylon 6 50\%cf fill } \\
\text { Celenese (2018) }\end{array}$ \\
\hline yield strength (psi) & (ASTM D638) & 6,400 & 4,600 & $\begin{array}{c}42,060 \mathrm{psi} \\
\text { (ISO 527-2/1A) }\end{array}$ \\
\hline $\begin{array}{c}\text { Youngs modulus } \\
\text { (psi) }\end{array}$ & (ASTM D638) & 320,000 & 186,000 & $\begin{array}{c}5,337,388 \\
\text { (ISO 527-2/1A) }\end{array}$ \\
\hline $\begin{array}{c}\text { impact strength (ft- } \\
\text { Ib/in) }\end{array}$ & $\begin{array}{c}\text { IZOD notched } \\
\text { (ASTM D256A) }\end{array}$ & $1 .-1.2$ & 1 & $\begin{array}{c}15.22 \mathrm{ft}-\mathrm{lb} / \mathrm{in} \\
(\text { ISO } 179 / 1 \mathrm{eA})\end{array}$ \\
\hline specific gravity & (ASTM D792) & 1.08 & 1.23 & 1.39 \\
\hline
\end{tabular}


Sources:

Avallone, E. A., Baumeister, T., \& Sadegh, A. (2007). Marks standard handbook for mechanical engineers (11th ed.). New York: McGraw-Hill.

Stratasys. (2015). FDM Nylon 12. Retrieved from

http://usglobalimages.stratasys.com/Main/Files/Material_Spec_Sheets/MSS_FDM_Nylon12.pdf

Celenese. (2018). Celestran PA6-CF50-12 AD3002 Black-PA6-CF50. Retrieved from

http://tools.celanese.com/material/pdf/152073/CELSTRANPA6CF5012AD3002BLACK?rnd=152086

8001115

\subsection{IMPACTS}

The goal of this project is to develop and demonstrate the impact additive manufacturing can have on both direct part substitution and tooling for robotic systems. A successful effort will result in a simpler design, reduced part count and lower cost low volume manufacturability. Lower cost will allow for expanded market penetration and expanded growth and employment opportunities for Transcend.

The success of the program so far has demonstrated that it is possible to design a lower cost Unmanned Ground Vehicle (UGV). The enclosure design and manufacturing approach will allow Transcend's partner Mantaro to complete development of the UGV being developed in conjunction with the a Israel-US Binational Industrial Research and Development (BIRD) Foundation. The UGV is being targeted to provide a cost effective and high performance UGV that can be used in homeland security applications such as search and rescue and policing. The UGV's ability to rapidly climb stairs makes it a unique tool for these applications. Mantaro has determined that there are more than 50,000 first responders facilities in the US that could benefit from the UGV. The successful completion of the project is expected to allow Transcend and Mantaro to grow rapidly with the expected addition of more than 20 employees in the first year of UGV production. In addition to domestic opportunities Mantaro has identified export markets in Israel (through a partnership with Beeper via a BIRD grant) and India with a partnership with an Indian company.

\subsection{CONCLUSIONS}

Phase 1 has demonstrated that the design goals can be achieved using FDM manufacturing techniques to prototype the UGV enclosures. Phase 2 of the program will allow the UGV enclosure design to be finalized and the fabrication of compression mold tooling. The low cost manufacturing approach is a critical component in allowing Transcend and Mantaro to deliver the envisioned stair climbing UGVs to first responders. This effort will be combined with ongoing efforts at Mantaro to develop new control electronics, drive motors, software and integrate communications systems and environmental sensors that will complete the overall design of the search and rescue UGV.

\section{PARTNER BACKGROUND}

Robotic locomotion has been a long standing research challenge. Wheeled vehicles are very efficient but have limitations when traveling off road or over obstacles. Tracked vehicles can achieve great traction but are very energy inefficient and have poor maneuverability. Legged robotic platforms have high mobility but are extremely complex and energy inefficient. Transcend Robotics has developed a hybrid tracked vehicle that overcomes some of the limitations of conventional tracked 
vehicles with a novel six track topology. Furthermore, the body is segmented into three sections with compliant couplings between the sections to enable passive conformal terrain matching.

This simple design modification enables great mobility enhancement. First, segmenting the single track into three sections enables low friction turning capability. Second, the passive compliance between the sections enables easy terrain maneuvering. The simplicity of the design enables great maneuverability without complex and expensive sensing and control. Applications include not only first responders and Department of Defense, but the technology is scalable to larger earth moving equipment. 